\title{
Qualidade da educação, jornada ampliada \\ e valorização da escola
}

\section{Quality of education, extended day and school valorization}

\section{Cleomar Locatelli}

Universidade Federal do Tocantins (UFT), Campus de Tocantinópolis (TO) - Brasil

\section{Resumo}

O texto trata da ampliação da jornada escolar como um fenômeno atual, importante na política educacional, relacionando-a às discussões sobre a questão da qualidade do ensino e de sua avaliação. O trabalho foi realizado tendo como base os dados da rede pública de ensino do estado do Tocantins, onde buscamos analisar a aferição da qualidade através dos testes padronizados e a expansão da jornada escolar ampliada. Verifica-se, diante das experiências existentes, que a jornada escolar, para que possa ser um critério de qualidade para educação pública, deve permitir a valorização da escola, podendo se tornar uma oportunidade para superação das suas limitações estruturais e conceptuais.

Palavras-chave: Jornada ampliada, Qualidade, Avaliação, Escola, Política educacional

\section{Abstract}

This paper covers the extension of school day as an important phenomenon in current educational policies, in relation to discussions on the issue of education quality and its evaluation. The work has been performed based on data from the public schools in the state of Tocantins, where we have analyzed the measurement of quality through standardized tests and the expansion of the extended school day. Given the existing experience, the school day, in order to be a quality criterion for public education, should allow the appreciation of school and become an opportunity to overcome their structural and conceptual limitations.

Keywords: Extended school day, Quality, Evaluation, School, Educational politics

\section{Introdução}

Neste trabalho, parte-se da compreensão de que a realidade escolar envolve um conjunto muito abrangente de possibilidades e efeitos, refletidos na vida e nas relações sociais dos sujeitos envolvidos. Assim, embora reafirmando a importância da avaliação, compreendemos que a aferição dos resultados ou da qualidade dos trabalhos realizados na escola, principalmente quando focados no produto final, serão sempre parciais, visto que se referem a um recorte da realidade e não a sua totalidade. $E$ esse recorte, além de ter ligação direta (ou indireta) com a concepção de educação que se tem, será determinado por variáveis relacionadas ao tempo, ao espaço e aos interesses dominantes. 
Nesse sentido, buscamos discutir a questão da qualidade da educação em relação à ampliação da jornada escolar, com o objetivo de analisá-la, como um indicador para verificação da qualidade da educação. Para isso, nos amparamos em alguns dados da educação básica na rede pública do estado do Tocantins, considerando, sobretudo, os resultados da avaliação em grande escala e suas possibilidades de contribuir para a melhoria da qualidade do ensino e o fortalecimento da escola.

Na primeira parte do trabalho, apresentaremos algumas definições e discussões que permeiam o debate sobre a qualidade da educação, destacando os principais modelos utilizados e sua trajetória dentro da realidade produzida pela experiência brasileira. Além disso, considerando as ações mais recentes para aferir a qualidade, com base no Índice de Desenvolvimento da Educação Básica (Ideb), discutiremos alguns resultados gerais dentro da realidade do estado do Tocantins.

Numa segunda parte, tratamos do processo de ampliação do tempo escolar, levando em conta suas possibilidades como critério para avaliação da qualidade da educação. Verifica-se aqui, não apenas as categorias de análise e as concepções presentes na discussão atual sobre o tema, mas também suas experiências na realidade educacional brasileira.

$\mathrm{Na}$ terceira parte, apresentamos um conjunto de dados sobre o prolongamento do tempo escolar e sobre a escola de tempo integral no Tocantins, identificando sua abrangência em comparação com o cenário nacional.

Observa-se, em síntese, que a escola, enquanto espaço historicamente privilegiado, no que se refere à realização do processo educativo formal e institucionalizado, nem sempre tem tido a centralidade necessária na discussão sobre qualidade da educação. Compreendemos que a inobservância de suas potencialidades e limites torna a avaliação incompleta e limitada como referencial para o planejamento. Por isso, a escola, não deve ser só avaliada, mas, principalmente, concebida a partir de uma perspectiva de educação integral, sendo um espaço de aprendizado rigoroso das ciências e do exercício da autonomia.

Como afirma Nosella (2007, p.149), "essa concepção de escola de rigor científico e de liberdade responsável aproxima-se da ideia de escola de tempo integral, ou melhor, de educação plena". Em outras palavras, uma escola que garanta o desenvolvimento intelectual, físico e tecnológico, possibilitando ao aluno um 
conhecimento rigoroso e, ao mesmo tempo, dando-lhe possibilidade de desenvolver sua criatividade e autonomia, não será constituída a partir de um processo de negação da própria escola.

\section{Sobre a avaliação da qualidade nas escolas e redes de ensino}

A avaliação da qualidade da educação é sempre um ponto que merece atenção, pela complexidade e variedade de questões envolvidas. De forma geral, dado a extensão dos intervenientes que podem influir no processo, podemos considerar que qualquer tentativa de executar essa tarefa pressupõe certa definição de questões elegíveis. $E$, nesse sentido, aqueles que discutem o tema ou que atuam nas políticas de avaliação buscam defender os determinantes que consideram mais relevantes.

No entanto, devemos levar em conta que o conceito de qualidade na educação não é algo estático, tem variações importantes, dependendo do local e do momento histórico. Para Dourado e Oliveira (2009, p. 203) “[...] qualidade é um conceito histórico que se altera no tempo e no espaço, ou seja, o alcance do referido conceito vincula-se às demandas e exigências sociais de um dado processo histórico".

A avaliação da qualidade educacional na atualidade é feita por uma verificação dos níveis de desempenho dos estudantes e por meio de teste de proficiência, que considera algumas áreas de conhecimento. Não se trata de uma apreciação dos níveis civilizatórios da sociedade, dos níveis de criatividade das empresas e dos trabalhadores em geral, ou da capacidade das pessoas de viverem juntos e de serem felizes. Opta-se por medir o produto final da escola, dentro de uma expectativa de aprendizagem que faz um recorte de conteúdos, estabelecendo o que deve ou não ser prioridade para a escola. Ainda que haja um relativo consenso sobre a importância da ação dos pais, dos meios de comunicação e de outras relações sociais como meios "educativos", geralmente, esses não são tomados como elementos de avaliação.

As escolas e as redes de ensino, como campo da educação formal intencionalmente sistematizada, embora sejam responsabilizadas pelos resultados, positivos ou negativos da avaliação, também não têm sido avaliadas quanto à capacidade de realizar aquilo que é esperado delas. Ou seja, não se tem levado em consideração suas especificidades conceptuais, suas estruturas e seus processos.

Fernandes e Gremaud (2009) percebem que a avaliação de escolas e de redes educacionais pode se dar em dois níveis distintos: conceitual - o que se pode esperar 
da escola (as diversas possibilidades de aprendizado e a limitação das medidas de resultados); e técnico-operacional - criação de indicadores para medir os resultados.

No caso do primeiro nível, estariam envolvidas questões sobre o que se ensina e o que se aprende na escola, sobre a elaboração do currículo e das diretrizes educacionais, bem como sobre os diversos aprendizados que as escolas, na relação com a sociedade de forma geral, podem produzir. A avaliação da escola no nível técnico-operacional, segundo os autores acima citados, pode ser verificada através de dois tipos de medidas: avaliação de insumos e processos e avaliação de resultados. Em relação aos insumos e processos são considerados, principalmente, infraestrutura das escolas, condições de trabalho e formação de professores, organização curricular, jornada escolar, autonomia financeira e gestão participativa. Em relação aos resultados, são considerados, basicamente, o desempenho em testes padronizados e o fluxo escolar: aprovação, reprovação, abandono.

Na Lei de Diretrizes de Bases da Educação Nacional (Ldben 9394/1996), a referência à qualidade é relacionada à variedade e quantidade de insumos por aluno. É isso que se observa no Art. $4^{\circ}$, inciso IX, quando os padrões mínimos de qualidade de ensino, são definidos "como a variedade e quantidade mínimas, por aluno, de insumos indispensáveis ao desenvolvimento do processo de ensino aprendizagem".

Porém, logo a seguir, no Art. 9ํㅗㄴ inciso VI, essa mesma lei determina que a União se incumbirá de "assegurar processo nacional de avaliação do rendimento escolar no ensino fundamental, médio e superior, em colaboração com os sistemas de ensino, objetivando a definição de prioridades e a melhoria da qualidade do ensino." Fica claro, portanto, que a avaliação terá como foco o rendimento escolar e, dá a compreender que tal ação, além de permitir a definição de prioridades, leva, por si só, à melhoria da qualidade do ensino.

Para Dourado, Oliveira e Santos (2007, p. 6)

[...] a qualidade da educação é um fenômeno complexo, abrangente e que envolve múltiplas dimensões, não podendo ser apreendido apenas por um reconhecimento da variedade e das quantidades mínimas de insumos considerados indispensáveis ao desenvolvimento do processo de ensino-aprendizagem, e muito menos, pode ser apreendido sem tais insumos.

No caso brasileiro, a definição de padrões mínimos de qualidade considerando uma "variedade e quantidade mínima, por alunos, de insumos indispensáveis ao desenvolvimento do processo de ensino aprendizagem", como proposto pela Ldben, 
assim como a análise dos processos educativos desenvolvidos nas escolas, ainda não compõem a agenda para avaliação da qualidade do ensino. Historicamente, outros indicadores de qualidade têm sido concretamente adotados:

De um ponto de vista histórico, na educação brasileira, três significados distintos de qualidade foram construídos e circularam simbólica e concretamente na sociedade: um primeiro, condicionado pela oferta limitada de oportunidades de escolarização; um segundo, relacionado à ideia de fluxo, definido como número de alunos que progridem ou não dentro de determinado sistema de ensino; e, finalmente, a ideia de qualidade associada à aferição de desempenho mediante testes em larga escala. (OLIVEIRIA; ARAÚJO, 2005, p. 8)

A medição da qualidade por meio de testes em larga escala tornou-se, nos últimos anos, uma ação bem presente em nosso meio. De forma geral, ainda que possamos questionar sua legitimidade pela generalização dos resultados e pela insuficiência dos dados, quando nos referimos à qualidade da educação no Brasil, em uma unidade da federação ou uma escola, esse é o único parâmetro que encontramos.

Segundo Fernandes e Gremaud (2009), a avaliação da aprendizagem passou de uma tarefa exclusiva de sala de aula, a elemento central na avaliação das escolas e sistemas de ensino, com objetivo de responsabilização (accountability). Esse processo, segundo os autores, embora possa apresentar alguma singularidade conforme o tempo e o espaço, reúne as seguintes características gerais: avaliação com ênfase no aprendizado do aluno por testes padronizados (pode incluir outros indicadores); os professores e gestores são corresponsáveis; e se busca estabelecer um sistema de reforço (positivo ou negativo) relacionado aos resultados.

De forma geral, como propõe os autores acima citados, esses programas de avaliação partem do princípio que, em grande medida, a qualidade da educação estaria relacionada a alguma mudança de práticas e hábitos de professores e gestores. Ou seja, que a prática, ou comportamento dos professores e diretores, explicaria o desempenho e que estariam ao seu alcance as mudanças de postura ou de metodologia para a melhoria dos resultados.

\section{O Índice de Desenvolvimento da Educação Básica (Ideb) e a qualidade da educação no Tocantins}

O Ideb tem se tornado, nos últimos anos, a mais importante referência no Brasil para determinar a qualidade da educação básica. A definição do índice de qualidade é amparada em dois indicadores: o resultado de testes padronizados, aplicados em larga 
escala, em todas as escolas e a média do rendimento escolar, conhecida também como fluxo escolar, que considera a taxa de sucesso (progressão) dos alunos envolvidos.

Sendo divulgados a cada dois anos, esses resultados possibilitam a construção de um quadro para indicar se a educação, numa escola ou numa rede de ensino, estaria ou não proporcionando alguma melhoria na sua qualidade, se estaria ou não se aproximando das metas estabelecidas. Da mesma forma, esses índices têm permitido a comparação com os resultados de outras unidades, viabilizando a realização do chamado ranqueamento.

Com base nesses parâmetros, no Gráfico 1, verifica-se que houve um contínuo crescimento da qualidade da educação no ensino fundamental primeira fase, realizada nas escolas da rede estadual do Tocantins. Passou-se de um Ideb de 3.6 em 2005 para 5.1 em 2013. No que se refere ao alcance da meta, que foi estabelecida a partir de 2007, verifica-se que, em relação a esse nível de ensino, a rede estadual vem se mantendo acima da meta, estabelecida em 4.7 para 2013. Se compararmos os índices acima ao desempenho de toda a educação pública do estado do Tocantins, para os anos iniciais do ensino fundamental, verificaremos que o desempenho da rede estadual se apresenta ligeiramente melhor em 2013, visto que mostra um índice de 5.1, enquanto o de todo o estado é de 5.0.

Faz-se necessário notar, no entanto, que tais resultados positivos do Ideb no Tocantins têm uma importante relação com o fluxo escola do ensino fundamental primeira fase. Em 2013, esse indicador ficou em 0.95, revelando que nesse nível de ensino de cada 100 alunos matriculados, 95 estão progredindo para a etapa seguinte.

Gráfico 1 - Ideb do ensino fundamental primeira fase da rede estadual do Tocantins (2005 a 2013)

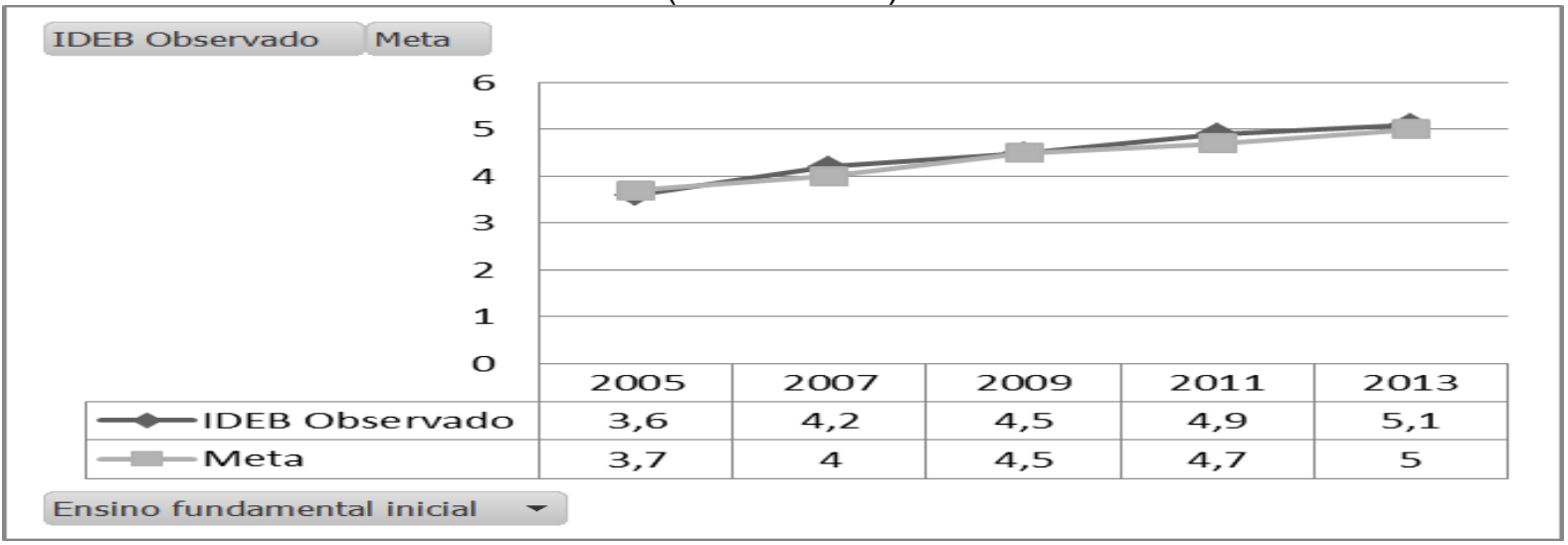

Revista Educação Online Rio de Janeiro, n. 22, mai-ago 2016, p. 89-106 
O Gráfico 2, que mostra o desempenho da rede estadual de ensino do Tocantins na segunda fase do ensino fundamental, apresenta uma realidade diferente. Como se pode observar, até 2011, com Ideb de 3.9, ainda se mantinha acima da meta estabelecida para aquele ano, porém, em 2013, os resultados demonstraram, não só um distanciamento da meta, que foi estipulada em 4.2, como também evidenciou uma queda em relação ao último índice, ficando com Ideb de 3.7.

Faz-se necessário destacar que uma das causas para o fraco desempenho em 2013, em relação à segunda fase do ensino fundamental, está relacionada ao que se apresenta no fluxo escolar. Nesse caso, diferente do que ocorreu com a primeira fase do ensino fundamental, o fluxo escolar ficou em 0.82, puxando para baixo o resultado do índice final. Cabe ressaltar que, caso o fluxo escolar apresentasse a mesma média observada para os anos iniciais do ensino fundamental, o índice não só ficaria maior em relação ao ano anterior, como teria superado a meta, ficando em 4.3.

Gráfico 2 - Ideb do ensino fundamental segunda fase da rede estadual do Tocantins (2005 a 2013)

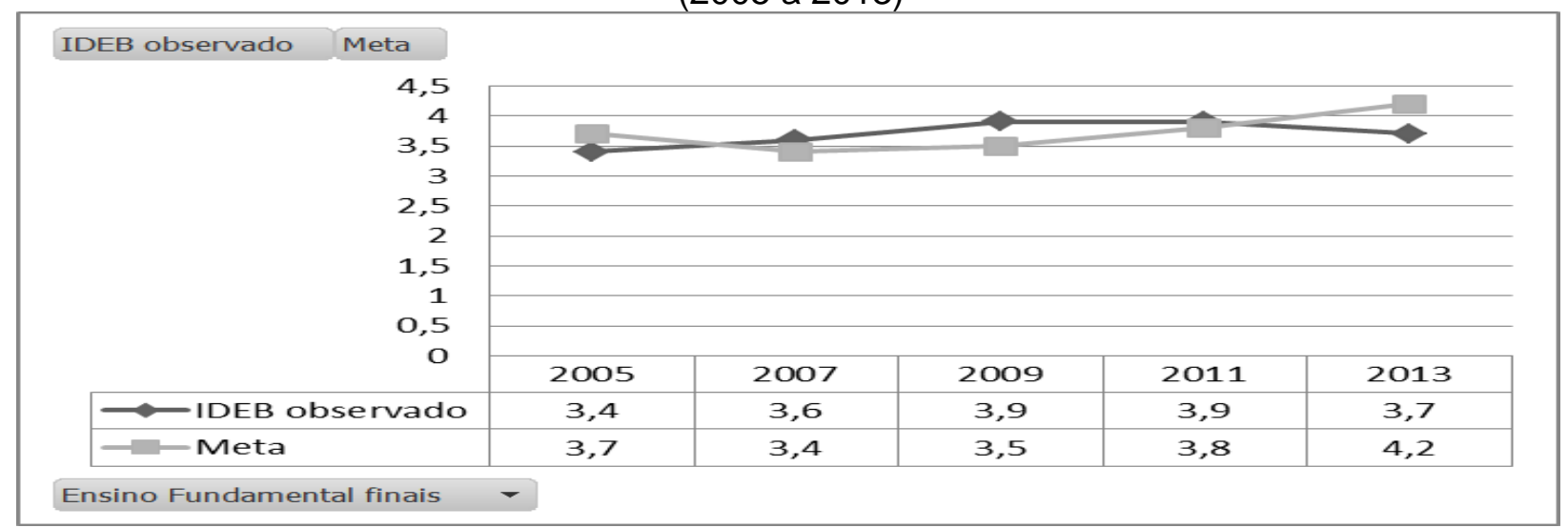

Fonte: MEC/INEP, 2013.

O Gráfico 3, referente aos resultados do ensino médio no Tocantins, basicamente repete o resultado já observado nos anos finais do ensino fundamental. $O$ resultado do Ideb, que até 2011 apresentava um lento, porém contínuo crescimento, revela uma queda na qualidade do ensino. O índice, que saiu de 2.9 em 2005 e chegou a 3.5 em 2011, caiu para 3.2 em 2013, ficando também abaixo da meta que foi estipulada em 3.4 neste mesmo ano. 
No caso do ensino médio, também observamos o fenômeno da taxa média de aprovação dos estudantes na etapa de ensino (fluxo), puxando a nota para baixo. A composição da nota do Ideb contou, em 2013, com 3.87 no resultado do teste padronizado e um uma nota de fluxo escolar de 0.82. Da mesma forma, podemos observar que, caso o fluxo escolar apresentasse um resultado semelhante ao constatado nos anos iniciais do ensino fundamental (0.95), não só teríamos a manutenção da elevação do índice final em relação ao ano anterior, como o resultado teria ficado acima da média.

Gráfico 3 - Ideb do ensino médio da rede estadual do Tocantins (2005 a 2013)

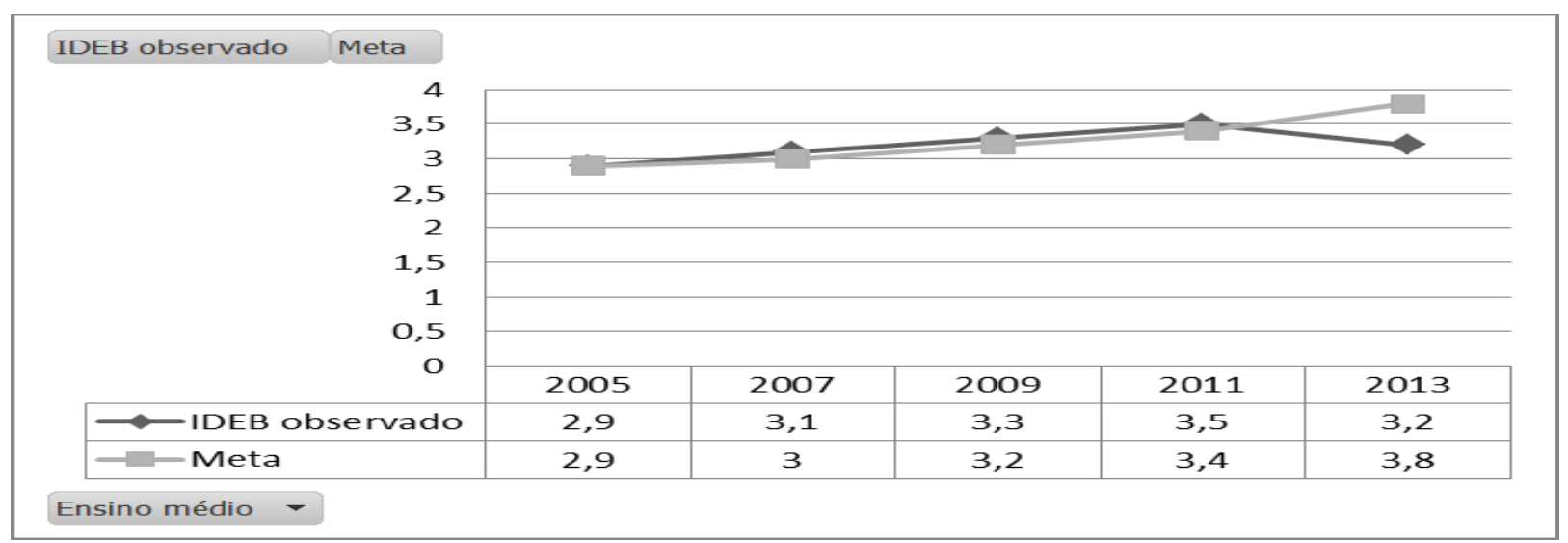

Fonte: MEC/INEP, 2013

Esse importante significado dos resultados do fluxo escolar para a composição da média final do Ideb no Tocantins, ainda que não façamos uma análise mais aprofundada em relação ao possível sentido oposto das taxas de aprovação e dos testes de proficiência aplicados em grande escala, reflete uma situação em que a margem de manobra das unidades escolares para alcançar bons resultados, parece ter chegado a um limite. Ou seja, a melhoria do fluxo, "até mesmo com aprovação automática”, começa a deixar de ser uma alternativa viável para a elevação do Ideb, mesmo em contextos em que, via-de-regra, espera-se um baixo desempenho dos alunos na proficiência (nos testes padronizados).

Assim, a divulgação dos resultados do Ideb no estado do Tocantins, ao ranquear escolas, acirrar a competição e criar uma cobrança, por via da opinião pública, a fim de melhorar os resultados, não tem se mostrado capaz de criar uma motivação contínua para melhorar os índices de qualidade. Por outro lado, podemos constatar também que a divulgação desses índices não parece ser suficiente - do ponto de vista do conjunto de fatores que envolvem o processo de ensino e 
aprendizagem na escola - para revelar a qualidade da educação, das escolas ou dos sistemas de ensino.

Verifica-se que outros elementos, sobretudo, relacionados aos insumos e processos deverão ser considerados. Questões que atentem para a realidade dos estudantes e para as condições concretas, humanas e materiais, de tempo e espaço das escolas, deverão ter algum lugar nas avaliações. E é nessa perspectiva que se busca discutir o prolongamento do tempo escolar, verificando suas possibilidades enquanto critério de avaliação da qualidade do ensino e sua emergência como política educacional, sobretudo no estado do Tocantins.

\section{O prolongamento do tempo escolar como qualidade}

Como já destacamos anteriormente, a partir de Oliveira e Araújo (2005), a qualidade da educação no Brasil tem apresentado três tipos de significados ao longo do tempo: a) acesso à escola, universalização do atendimento; b) eliminação do fracasso escolar, redução dos índices de reprovação e abandono; e c) aplicação de testes de conhecimento em grande escala para aferição de desempenho.

Embora o acesso à escola não seja mais considerado um problema central, visto que, no Brasil, para ensino fundamental e médio, basicamente se "resolveu" o problema do atendimento, devemos considerar que para a educação infantil (creches e pré-escola) e para o ensino superior ainda persiste a falta de vagas.

No entanto, mais do que a disponibilidade de vagas, a questão do acesso como critério de qualidade deve ser pensada como possibilidade e oportunidade de aprender, como democratização do conhecimento e como direito à educação. E é nesse sentido que buscamos desenvolver uma discussão, considerando os seguintes questionamentos: O prolongamento do tempo escolar pode ser tomado com critério de qualidade? Quais são as concepções e orientações referentes ao prolongamento do tempo escolar predominantes no Brasil? E como tem se dado o avanço da ampliação do tempo escolar?

Essas questões se tornam oportunas porque, em primeiro lugar, como observamos anteriormente, a divulgação do desempenho nos testes de proficiência e do fluxo escolar através do Ideb, criando ranques e estimulando a competição através da comparação, já se mostra esgotada como estratégia para melhoria da qualidade da educação. Ainda que se possa constatar a importância dos testes de proficiência e da 
análise da taxa média de aprovação dos alunos para diagnosticar a qualidade do ensino, fica cada vez mais claro que esses indicadores não estão funcionando como estímulo para que se alcance patamares mais elevados de qualidade, ficando também evidente sua insuficiência para traduzir as potencialidades e limites das escolas e redes de ensino no Brasil.

Em segundo lugar, como previsto na Ldben Art. 4ํㅜㄹ a qualidade da educação deverá ser observada por meio da variedade e quantidade mínimas, por aluno, de insumos indispensáveis ao desenvolvimento do processo de ensino aprendizagem. Ou seja, os insumos e processos se tornam dimensões importantes quando se considera que o ambiente de aprendizado e sua estrutura organizacional não podem ser ignorados como estímulos à aprendizagem, e que, certamente, essa dimensão não será revelada por meio de um teste padronizado de proficiência. Da mesma forma, ao considerar essas dimensões, que envolvem infraestrutura, formação de professores, organização administrativa e curricular, entre outros, estabelece-se uma clara valorização da instituição escolar como espaço social e político, que deve ter responsabilidade e autonomia para desenvolver o processo educativo.

Em terceiro lugar, observamos que o tempo tem se tornado uma questão-chave para que a escola dê conta dos seus desafios em relação ao conhecimento que espera das novas gerações. Sobretudo para as regiões mais pobres do país e para as famílias com baixo poder econômico, o tempo escolar diário que possibilite ao estudante ter acesso aos bens culturais que historicamente foram acessíveis a poucas pessoas, revela-se de fundamental importância para a formação das futuras gerações. Ainda que não se possa estabelecer uma relação direta e definitiva da duração da jornada escolar com a consistência e o volume da aprendizagem, vários estudos têm demostrado que, dentre as diversas variáveis que podem influir nos "efeitos escolares", o tempo de dedicação figura entre os mais importantes. Isso se torna verdadeiro, sobretudo, quando se quer desenvolver uma educação integral, considerando, inclusive, o aprendizado da democracia para a vida em sociedade como uma tarefa da escola.

Nas palavras de Cavaliere (2007, p. 1.022),

Numa escola de tempo integral, as atividades ligadas às necessidades ordinárias da vida (alimentação, higiene, saúde), à cultura, à arte, ao lazer, à organização coletiva, à tomada de decisões, são potencializadas e adquirem uma dimensão educativa. Diferentemente, a rotina otimizada e esvaziada de opções em uma escola em turno parcial, imediatamente centrada nos conteúdos escolares, dificilmente pode propiciar esse tipo de vivência. Nesse sentido, ou seja, entendendo-se mais tempo como 
oportunidade de uma outra qualidade de experiência escolar, é que a escola de tempo integral pode trazer alguma novidade ao sistema educacional brasileiro.

A emergência da ampliação da jornada escolar no Brasil, segundo Ribetto e Mauricio (2009), tem sido discutida a partir de quatro categorias de análise: jornada escolar; política educacional-política pública; práticas educativas; e democratização da educação. Para Cavaliere (2007), as discussões sobre esse fenômeno no Brasil revelam quatro concepções de escola de tempo integral: assistencialista (substituir a família); autoritária (prevenir o crime); democrática (mais acesso ao conhecimento); multissetorial (feita fora da escola).

Entretanto, no que se refere às experiências concretas de ampliação da jornada escolar atualmente no Brasil, podemos observar claramente duas vertentes: a primeira se refere à organização do espaço da escola, estruturando-a para um funcionamento de tempo integral. A segunda busca ampliar a jornada de estudo dos alunos, com a utilização do espaço fora da escola, onde o tempo integral seria para 0 aluno (CAVALIERE, 2009).

Na primeira vertente, segundo Miranda e Santos (2012), para educação integral seria necessário escola de tempo integral. Esse modelo está baseado nas experiências de Anísio Teixeira em 1950 - Salvador, com o Centro Educacional Carneiro Ribeiro e dos Centros Integrados de Educação Pública (Cieps) e Centro de Atenção Integral à Criança (Caics). Conforme Cavaliere (2009, p. 53), nesse modelo,

A ênfase estaria no fortalecimento da unidade escolar, com mudanças em seu interior pela atribuição de novas tarefas, mais equipamentos e profissionais com formação diversificada, pretendendo propiciar a alunos e professores uma vivência institucional de outra ordem.

Essas experiências têm avançado em muitas redes municipais e estaduais de ensino de vários estados do Brasil. O governo federal incentiva esse modelo de ampliação da jornada escolar, através da diferenciação dos fatores de ponderação para liberar os recursos do Fundo de Desenvolvimento da Educação Básica (Fundeb) e pela disponibilidade de recursos através do Programa Dinheiro Direto na Escola (PDDE). Suas particularidades devem ser observadas a partir de cada realidade específica em que se realiza.

Nas redes públicas de ensino com propostas de escola integral em andamento no Brasil, alguns projetos envolvem desde mudanças na estrutura física e reorganização das instituições escolares (como construção de novos prédios, incorporação de novos ambientes externos à escola e novas maneiras de utilização dos espaços existentes) até novas rotinas dos alunos em atividades relativas, essencialmente, aos esportes e às 
artes, em geral dissociadas das matérias escolares comuns. (MIRANDA; SANTOS, 2012, p. 1.084-5)

Porém, assim como são diversas as experiências, também são observadas algumas possíveis fragilidades desse modelo, entre eles podemos enumerar: o mito da escola salvadora que vai proteger a criança dos problemas do mundo "pervertido", descaracterizando o papel da escola; a inadequação das estruturas físicas das escolas pela simples adaptação de escolas de tempo parcial; a manutenção da proposta pedagógica anterior; e a utilização do tempo escolar de forma improvisada.

$\mathrm{Na}$ segunda vertente, temos a ampliação da jornada diária escolar com a utilização de espaços fora da escola. Esse modelo tem como base a ideia de Cidade Educadora, que deve ser uma importante extensão da escola. Para Cavaliere (2009, p. 53), nesse modelo de ampliação da jornada escolar,

A ênfase estaria na oferta de atividades diversificadas aos alunos no turno alternativo ao da escola, fruto da articulação com instituições multissetoriais, utilizando espaços e agentes que não os da própria escola, pretendendo propiciar experiências múltiplas e não padronizadas.

No âmbito do governo federal, esse modelo recebe um importante incentivo por meio do Programa Mais Educação. Os objetivos desse programa são: formular política nacional de educação básica em tempo integral; promover diálogo entre os conteúdos escolares e os saberes locais; favorecer a convivência entre professores, alunos e suas comunidades; disseminar as experiências das escolas que desenvolvem atividades de educação integral; convergir políticas e programas de saúde, cultura, esporte, direitos humanos, educação ambiental etc. (MEC/SECAD, 2009a).

Do ponto de vista econômico, às escolas que aderissem ao programa em 2014, seria disponibilizado, para todo o ano, através do Fundo Nacional de Desenvolvimento da Educação (FNDE), um valor de $\mathrm{R} \$ 80,00$ (oitenta reais) por turmas monitoradas de escolas urbanas e $\mathrm{R} \$ 120,00$ (cento e vinte reais) por turmas monitoradas de escolas rurais. Os recursos são depositados diretamente na conta das Unidades Executoras (UEx) das escolas nos moldes do Programa Dinheiro Direto na Escola (PDDE).

Os principais questionamentos em relação a esse modelo de ampliação da jornada escolar são: descaracterização do espaço escolar; ampliação do tempo que não é na escola, precarizando as práticas educativas; redução da responsabilização do Estado (voluntariado, espaços sociais, ONGs e instituições privadas); e improvisação, visto se constituir, em geral, numa ação desvinculada do projeto da escola. 
Uma das principais constatações sobre o modelo que amplia a jornada contando com espaços fora da escola, e mais particularmente sobre o Programa Mais Educação, é que ele tem se tornado uma forma de motivação para os estados e municípios adotarem a ampliação do tempo escolar de forma bastante reduzida e precária. Reduzida, porque, em geral, as escolas que realizam o programa não o fazem para todas as turmas, mesmo porque não dispõem de local e pessoal adequados para as atividades. Precário, por contar com uma disponibilidade de recursos muito reduzida e por depender de voluntários e de outras instituições para a realização das atividades.

Na opinião de Cavaliere (2009, p. 58),

Se houver uma excessiva fragmentação e inconstância na utilização do tempo suplementar, com oferta de atividades em vários locais e com agentes sem a preparação adequada, ele pode se transformar ou em mero "atendimento", com sentido limitadamente assistencialista, ou em mero "consumo", isto é, ocupação com atividades desconectadas de um projeto político-pedagógico, organizadas como uma espécie de "mercado".

Assim, consideramos aqui que a ampliação da jornada pode ser uma variável importante como critério de qualidade, no entanto, observando as experiências mais recentes na realidade brasileira, bem como as iniciativas do governo federal nessa direção, percebemos que o conceito de qualidade pode se tornar bastante particular, e até mesmo estreito, quando se trata de construir uma alternativa para diminuir o gasto com as políticas sociais e desresponsabilizar o Estado com a educação. Essa observação se torna ainda mais relevante, para que possamos acompanhar os desdobramentos da efetivação da meta 6 (seis) do Plano Nacional de Educação (PNE).

Aprovado pelo Congresso Nacional em seis de junho de 2014, o PNE procura estabelecer uma política para educação integral, sem deixar claro como se dará a política de financiamento e qual o padrão a ser adotado. Por outro lado, quando analisamos as estratégias para a implementação dessa meta, constatamos a permanência de uma orientação dúbia quanto à necessária adequação da infraestrutura e dos programas de ensino para uma escola de tempo integral. Grande parte das estratégias está propondo uma ampliação da jornada escolar com ênfase em atividade multissetorial, através de espaços e agentes fora da escola.

Como já destacamos anteriormente, em nossa compreensão, a adoção de uma perspectiva de qualidade mais abrangente de educação, pressupõe a existência de uma instituição escolar fortalecida, que tenha autonomia para atuar a partir de suas peculiaridades, que leve em conta o contexto socioeconômico dos estudantes, que 
tenha uma infraestrutura e uma jornada escolar condizente com as necessidades de aprendizado dos alunos.

O esvaziamento da escola não é compatível com uma concepção de qualidade que valorize a formação inicial e continuada de professores, que garante espaços apropriados para as diversas experiências de aprendizado, que propicie a produção e socialização de conhecimentos científicos e tecnológicos de forma crítica e reflexiva, que seja capaz de elaborar e implementar um Projeto Político Pedagógico compatível com as especificidades e necessidades da comunidade atendida.

\section{A emergência da ampliação da jornada escolar no Tocantins}

A seguir analisaremos os dados da rede pública de ensino no estado do Tocantins, considerando, a partir das matrículas de 2014, o avanço da ampliação da jornada no estado, tanto para o modelo de "aluno de tempo integral", como para "escolas de tempo integral", conforme definição de Cavaliere (2009).

Inicialmente, observamos que, em 2014, segundo dados disponíveis no portal FNDE/PDDE (2014), 360 escolares da rede estadual de ensino do Tocantins aderiram ao Programa Mais Educação, envolvendo, direta ou indiretamente, um total de 111.156 alunos. Já a adoção do regime de tempo integral, com ampliação da jornada dentro da própria escola, com indicação no censo escolar e contempladas pelo recurso do Fundeb, foram de 35.993 matrículas no ensino fundamental e 2.641 no ensino médio, abrangendo 49 escolas no total.

O Gráfico 4 apresenta os percentuais de alunos matriculados em escolas da rede estadual do Tocantins, nos dois modelos de ampliação da jornada escolar. Observa-se que os alunos matriculados em escolas com ampliação do tempo dentro da própria escola também são contemplados pelos recursos e computados nas estatísticas de regime integral do PDDE. Assim, dos 111.156 alunos contemplados, direta ou indiretamente pelo programa de ampliação da jornada nas escolas estaduais do Tocantins, 35.993, ou 34\% do total, estão matriculados em escolas em que a ampliação do tempo escolar se dá pelo regime de escola de tempo integral. 
Gráfico 4 - Jornada ampliada no estado do Tocantins - Alunos de tempo integral e escolas de tempo integral 2014.

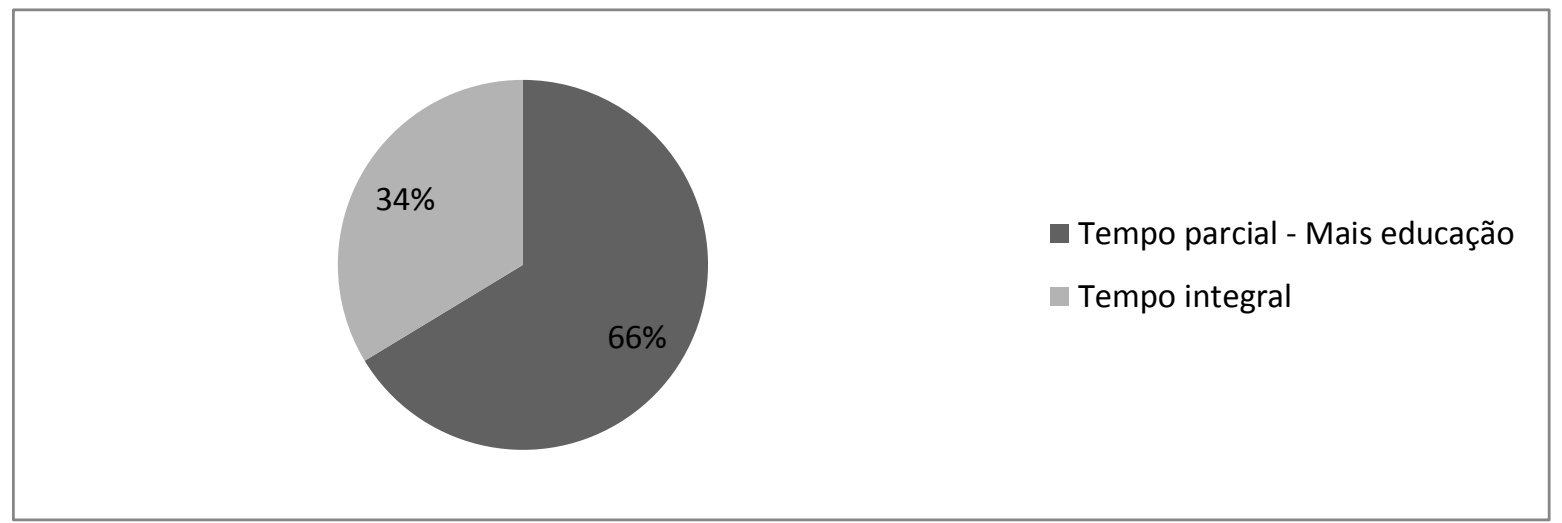

Fonte: FNDE/PDDE, 2014

No Gráfico 5, apresentamos o percentual de matrículas no estado do Tocantins, considerando as redes municipais e estaduais que adotaram escola de tempo integral para o ensino fundamental. Percebe-se que, em relação aos dados da matrícula para todo o Brasil, há um avanço significativo. Enquanto as matrículas em escolas de tempo integral no ensino fundamental para todo o Brasil estão em 11\%, no estado do Tocantins já alcança 26\%. Ou seja, 65.974 matrículas, das 253.686 do ensino fundamental no estado do Tocantins em 2013, foram para escolas de tempo integral.

Gráfico 5 - Percentual de matrículas em escolas de tempo integral, ensino fundamental, Tocantins, 2013.

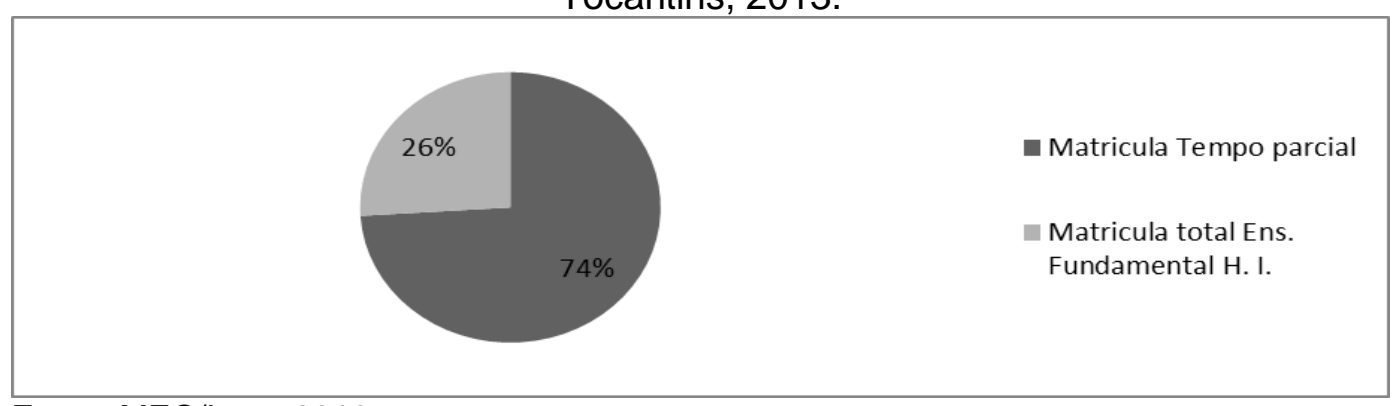

Fonte: MEC/Inep, 2013.

No Gráfico 6, procuramos detalhar os dados relativos aos percentuais de matrículas no ensino fundamental do Tocantins conforme a rede de ensino. Verificamos que a maior parte das matrículas, em 2013, em escolas de tempo integral no estado, está na rede estadual de ensino. Ou seja, considerando o total das matrículas em escola de tempo integral no estado, 54\% estão na rede estadual, $45 \%$ na rede municipal e apenas $1 \%$ nas escolas particulares. Em números, conforme dados do censo escolar (MEC/INEP, 2013), são 35.777 matrículas na rede estadual, 29.535 na rede municipal e 669 nas escolas particulares. 
Gráfico 6 - Percentuais de matrículas em escolas de tempo integral, ensino fundamental, no Tocantins conforme a rede de ensino, 2013.

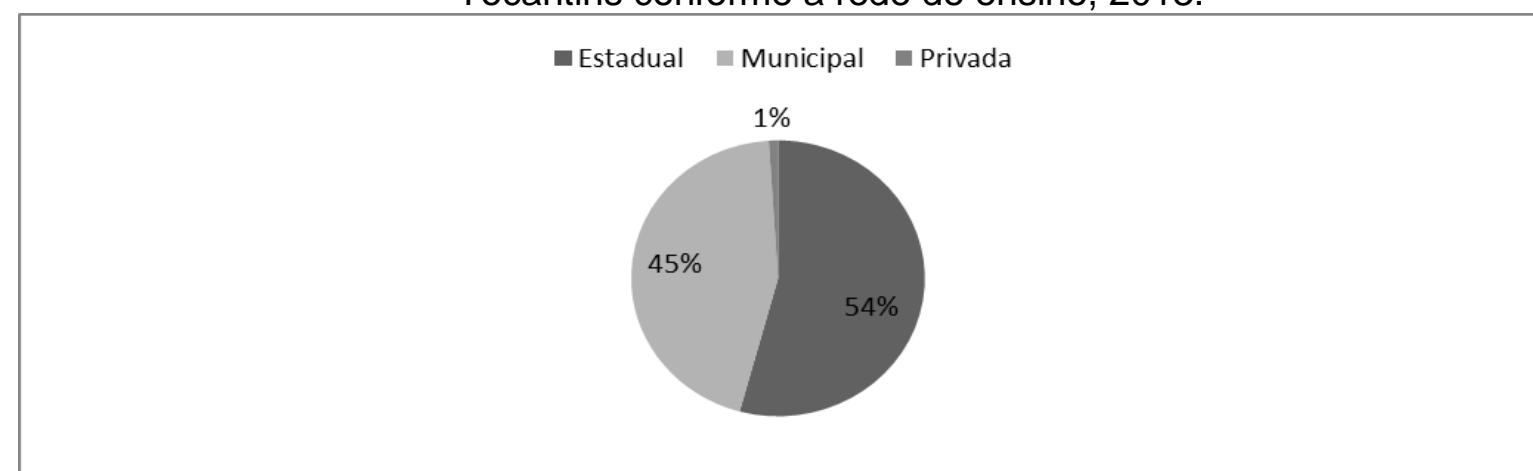

Fonte: MEC/INEP, 2013.

O Gráfico 7 faz um comparativo dos percentuais de matrícula em escolas de tempo integral de ensino médio no Brasil e no Tocantins em 2013. Observa-se que, para esse nível de ensino, o avanço da escola de tempo integral fica em torno de $6 \%$ no estado do Tocantins, um ponto percentual a mais que no total das matrículas do país.

Gráfico 7 - Percentuais de matrículas, ensino médio, em escolas de tempo integral:

Brasil $x$ estado do Tocantins.

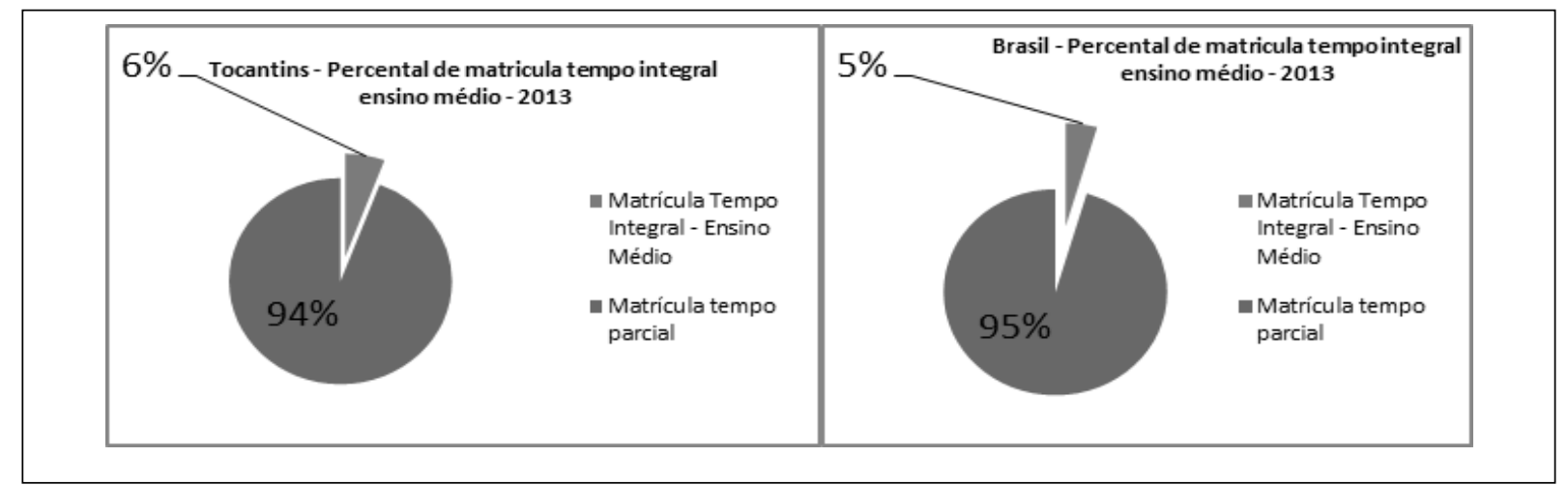

Fonte: MEC/INEP, 2013.

\section{Considerações finais}

A análise da ampliação da jornada escolar, a partir das iniciativas atuais, relacionando-as com as discussões sobre a qualidade da educação nacional, torna-se uma questão urgente, reveladora e estratégica. Principalmente se considerarmos o momento presente, diante do novo Plano Nacional de Educação - ainda que permeado por contradições - com espaços para que se ampliem as possibilidades de uma escola pública, gratuita e fortalecida.

Consideramos essa discussão urgente, porque se refere a um processo em curso, com escasso debate e com concepções, objetivos e interpretações bastante 
diversas. Ela também é reveladora, porque como demostramos acima, há no Brasil, atualmente, diversas iniciativas ligadas às redes municipais e estaduais de ensino que merecem atenção, seja em relação aos resultados positivos que estão alcançando, seja pelos desafios enfrentados. Tais experiências podem servir de parâmetros para que o avanço previsto no Plano Nacional de Educação possa estabelece-se em bases mais seguras. E é estratégica, porque se trata de uma possibilidade de fortalecimento da escola pública, fato que consideramos de extrema relevância.

Da mesma forma, ponderamos também que partes das experiências hoje em execução, seja no estado do Tocantins ou em outras unidades da federação, precisam ser repensadas, sob pena de se travestirem em uma reedição da escola flexível, elitista e reprodutora do status quo, como afirmou Saviani (1994), ao analisar a experiência da "Escola Nova" entre os professores da rede pública no Brasil e tendo como consequência o "afrouxamento da disciplina e a despreocupação com a transmissão de conhecimentos" (SAVIANI, 1994, p.22).

Com vimos, no caso do estado do Tocantins, há, não só a emergência dos dois modelos descritos (um que busca ampliar o tempo escolar fora do espaço escolar e outro que eleva a jornada dentro da própria escola), mas também inúmeras outras possíveis variações. As chamadas escolas de tempo integral têm sido constituídas de várias formas, muitas vezes estabelecendo sua viabilidade por arranjos e improvisações, tendentes a não se sustentarem no médio e longo prazo, bem como penalizando os profissionais da escola e os alunos, de modo que esses tendem a desenvolver uma conceituação negativa do que conhecem como ensino integral.

Por fim, sobre a qualidade do ensino e a emergência da ampliação da jornada escolar, podemos ressaltar, de um lado, as potencialidades favorecidas pela ampliação do tempo na escola e, por outro, os problemas decorrentes de uma possível implementação enviesada da escola de tempo integral. Como avaliou Cavaliere (2009, p. 61), "Construir uma escola, a mais justa possível, a mais democrática possível, com papel socializador efetivo, atenta aos novos saberes e questões do conhecimento, muito provavelmente incluirá a ampliação do seu tempo e a estabilidade de seus atores." No entanto, a falta de uma compreensão adequada desse fenômeno e de um amplo debate, sobretudo junto aos educadores e agentes públicos de modo geral, pode levar a atual emergência da ampliação da jornada escolar a mais uma experiência frustrada para o processo de educação no Brasil. 


\section{Referências bibliográficas}

BRASIL. Lei 9.394/96. Lei de Diretrizes e Bases da Educação Nacional (Ldben). DOU, Brasília, 23.12.1996. Disponível em: <http://www.planalto.gov.br/ccivil_03/Leis/L9394.htm>. Acesso em: 21/03/2016.

. FNDE/PDDE. Relação de Unidades Executoras (REx) - 2014. Secretaria de Educação do Estado do Tocantins. Disponível em: $<\mathrm{https}$ ://www.fnde.gov.br/pls/internet_pdde/internet_fnde.PDDEREX_4_PC?p_ano=201 4\&b_ver=3\&p_cgc $=25053083000108 \& p \_t i p=P \& p \_p r o g=Z 9>$. Acesso em: 08/11/14.

MEC/INEP. Censo escolar 2013. Disponível em: <http://portal.inep.gov.br/basica-censo> Acesso em: 25/02/2015.

. MEC/ SECAD. Educação Integral: texto de referência para o debate nacional. Brasília - DF, 2009b. Disponível em: <http://portal.mec.gov.br/dmdocuments/cadfinal_educ_integral.pdf >. Acesso em: 10/06/2016.

BRASIL. PNE, Lei no 13.005, de 25 de junho de 2014. Aprova o Plano Nacional de Educação -PNE e dá outras providências. Diário Oficial da União, Brasília - DF, quintafeira, 26 de junho de 2014.

FNDE/PDDE. Dados Estatísticos. (2014). Disponível em: <http://www.fnde.gov.br/programas/dinheiro-direto-escola/dinheiro-direto-escola-dadosestatisticos> Acesso em: 25/02/2015.

CAVALIERE, Ana Maria Villela. Tempo de escola e qualidade na educação pública. Educação \& Sociedade, v. 28, n. 100, p. 1.015-1.035, out. 2007. Disponível em: $<$ http://www.scielo.br/scielo.php?script=sci_arttext\&pid=S010173302007000300018\&lang=pt>. Último acesso em: 17/03/ 2014.

Escolas de tempo integral versus alunos em tempo integral. Em aberto, v. 22, n. 80, p. 51-63, abr 2009.

DOURADO, Luís Fernando; OLIVEIRA, João Ferreira de; SANTOS, Catarina de Almeida. A qualidade da educação: conceitos e definições. Série Documental: Textos para Discussão, v. 24, n. 22, p. 5-34, 2007.

DOURADO, Luís Fernando; OLIVEIRA, João Ferreira de. A qualidade da educação: perspectivas e desafios. Cadernos Cedes, v. 29, n. 78, p. 201-215, mai-ago 2009.

FERNANDES. Reynaldo; GREMAOD, Amaury. Qualidade da educação: avaliação, indicadores e metas. 2009.2 Disponível <http://www.cps.fgv.br/ibrecps/rede/seminario/reynaldo_paper.pdf>. Acesso em: $14 / 10 / 2014$.

MIRANDA, Marília Gouvea de; SANTOS, Soraya Vieira. Propostas de tempo integral: a que se destina a ampliação do tempo escolar?. Perspectiva, v. 30, n. 3, p. 1.073-1.098, set-dez $2012 . \quad$ Disponível em: <http://periodicos.ufsc.br/index.php/perspectiva/article/viewFile/2175795X.2012v30n3p1073/pdf_1 >. Último acesso em: 10/12/2013.

NOSELLA, Paulo. Trabalho e perspectivas de formação dos trabalhadores: para além da formação politécnica. Revista Brasileira de Educação, v.12, n. 34, p.137-151, 2007. 
OLIVEIRA, Romualdo Portela de; ARAUJO, Gilda Cardoso de. Qualidade do ensino: uma nova dimensão da luta pelo direito à educação. Revista Brasileira de Educação, n. 28, p.5-23, jan-abr 2005.

RIBETTO, Anelice; MAURíCIO, Lúcia Velloso. Duas décadas de educação em tempo integral: dissertações, teses, artigos e capítulos de livros. Em aberto, v. 22, n.80, p.137160, abr 2009.

SAVIANI, Demerval. Escola e democracia. Campinas: Mercado de Letras, 1994. 